\title{
Welcome to the 13th Volume of Nanomedicine
}

\author{
Joseph Martin*,1 \\ ${ }^{1}$ Future Medicine Ltd., Unitec House, London, N3 1QB, UK \\ * Author for correspondence: j.martin@futuremedicine.com
}

First draft submitted: 13 November 2017; Accepted for publication: 15 November 2017; Published online: 6 December 2017

To all of our readers, we are delighted to welcome you to volume 13 of Nanomedicine. I would like to take this opportunity to wish all of our readers a Happy New Year. Throughout this Foreword, I will present some of the journal highlights of 2017 in addition to looking forward to the year ahead.

Similar to 2016, we have seen great developments in the field of nanotechnology for medical applications. It is vital that the nanotechnology community continue to publish high quality work in this fascinating field in order to help see a more widespread use of this technology.

\section{Special focus issues}

Our special focus double issue centered on the fourth International Conference on Nanotechnology in Medicine (NANOMED16) was a particular highlight of 2017. This themed issue aimed to share a selection of the key studies at the conference, specifically focusing on the advances in biomaterial design and application for medical intervention.

- Issue 18 \& 19: 'Advances in biomaterial design and application for medical intervention' [1]

Special focus issues are a great way of showcasing the latest research in a specific subfield in nanomedicine. By having an entire journal issue dedicated to a topic, each article can focus on one aspect in detail, contributing to the bigger picture when they are all compiled together. I would like to give special thanks to our guest editor May Azzawi (Manchester Metropolitan University), without whom publication would not be possible.

\section{Article highlights}

Outside of our Special Focus issues, we have also published a number of outstanding manuscripts in the journal this year. I would like to draw your attention to some of the particular highlights of 2017.

Our most highly accessed article from volume 12 has been the review entitled 'Drug delivery to the eye: what benefits do nanocarriers offer?' by Joseph and Venkatram [2]. This review summarizes the recent advances in ocular therapy, thanks to nanotechnology. The authors also discuss the distribution and fate of these nanocarriers.

Editorial style content has also been popular in 2017, our second most accessed article was the Editorial entitled 'Magnetic nanoparticles in cancer therapy: how can thermal approaches help?' by Kolosnjaj-Tabi and Wilhelm (University Paris Diderot) [3]. The authors discuss the major advantages and potential applications of magnetic nanoparticles.

Nanomedicine also publishes leading primary research articles which are attracting a lot of attention. Our most popular research article from the past year was a piece by Janeczek et al. entitled 'PEGylated liposomes associate with Wnt3A protein and expand putative stem cells in human bone marrow populations' [4]. In this study, the team aimed to demonstrate the efficacy of PEGylated liposomes in promoting expansion of osteoprogenitors from human bone marrow.

\section{Geographical spread of our contributors}

As the interest in this fascinating field continues to grow, we continue to see a change in the readership of Nanomedicine. Asia makes up a high proportion of our readership (43\%), specifically with China making up 25\%, almost equal to the USA (24\%). We have also seen a large proportion of European readers, in particular, the UK

Future Medicine 


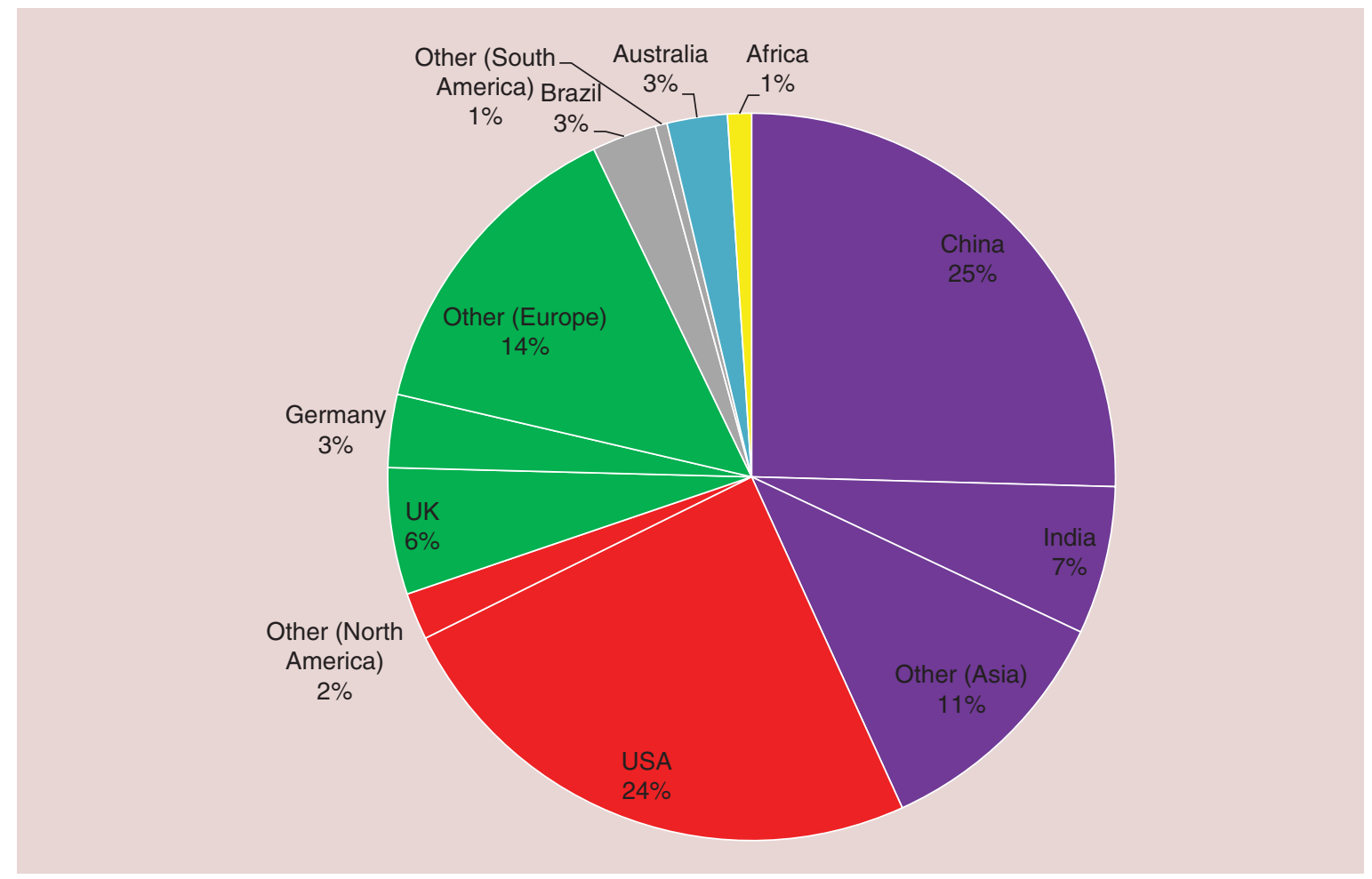

Figure 1. Proportion of readership demographics for Nanomedicine in 2017.

(6\%) and Germany (3\%) (Figure 1). Nanomedicine continues to welcome both readers and content from across the world.

\section{Twitter}

Social media continues to be a great way to showcase content highlights, journal updates and key news from the field. I have thoroughly enjoyed engaging with our readers and authors on these platforms and encourage anyone on Twitter to follow us (@fsgnnm) [5].

\section{Conclusion}

I would like to take this opportunity to thank everyone that has made Nanomedicine a success over this last year. This includes our Editorial Board for providing their invaluable advice and assistance, authors for submitting their high quality work and peer reviewers for providing expert feedback on the submissions. We continue to welcome unsolicited article proposals, and would be delighted to hear from you if you are interested in submitting to the journal.

I am looking forward to collaborating with you all over the next year and hope to see yet another volume of fascinating content in 2018.

Financial \& competing interests disclosure

$J$ Martin is an employee of Future Medicine Ltd. The author has no other relevant affiliations or financial involvement with any organization or entity with a financial interest in or financial conflict with the subject matter or materials discussed in the manuscript apart from those disclosed.

No writing assistance was utilized in the production of this manuscript.

\section{References}

1 Azzawi M. Advances in biomaterial design and application for medical intervention. Nanomedicine 12(18), 2151-2152 (2017).

2 Joseph RR, Venkatraman SS. Drug delivery to the eye: what benefits do nanocarriers offer? Nanomedicine 12(6), 683-702 (2017). 
3 Kolosnjaj-Tabi J, Wilhelm C. Magnetic nanoparticles in cancer therapy: how can thermal approaches help? Nanomedicine 12(6), 573-575 (2017).

4 Janeczek AA, Scarpa E, Horrocks MH et al. PEGylated liposomes associate with Wnt3A protein and expand putative stem cells in human bone marrow populations. Nanomedicine 12(8), 845-863 (2017).

5 Twitter: Nanomedicine. https://twitter.com/fsgnnm 
(

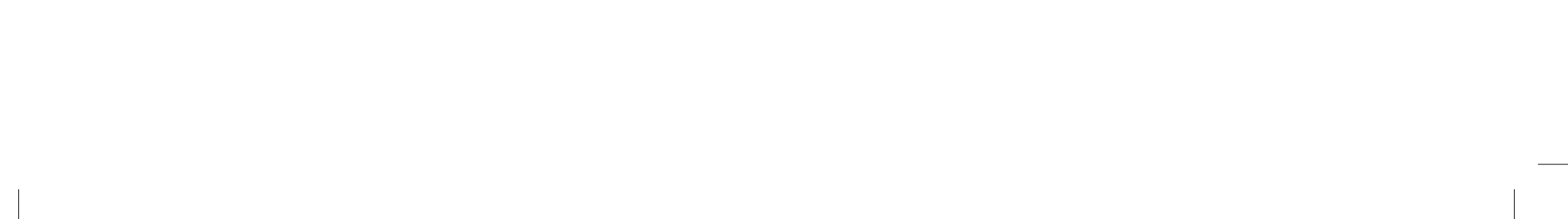

